\title{
Soil dissipation and bioavailability to earthworms of two fungicides under laboratory and field conditions
}

\author{
Sylvie Nélieu ${ }^{\mathrm{a}^{\mathrm{k}}}$, Ghislaine Delarue ${ }^{\mathrm{a}}$, Joël Amossé ${ }^{\mathrm{b}, 1}$, Sylvain Bart ${ }^{\mathrm{b}, 2}$, Alexandre R.R. Péry ${ }^{\mathrm{b}}$, Céline Pelosi ${ }^{\mathrm{b}}$ \\ ${ }^{a}$ UMR ECOSYS, INRA, AgroParisTech, Université Paris-Saclay, 78850, Thiverval-Grignon, France \\ ${ }^{\mathrm{b}}$ UMR ECOSYS, INRA, AgroParisTech, Université Paris-Saclay, 78026, Versailles, France
}

\begin{abstract}
* Corresponding author (S. Nélieu): UMR ECOSYS INRA AgroParisTech, Bâtiment EGER, Avenue Lucien Brétignières, 78850 Thiverval Grignon, France. Tel: (+33)1.30815283. E-mail: sylvie.nelieu@inra.fr
\end{abstract}

\begin{abstract}
The representativeness of laboratory studies of the fate of pesticides in soil in field conditions is questionable. This study aimed at comparing the dissipation and bioavailability to earthworms of two fungicides, dimoxystrobin (DMX) and epoxiconazole (EPX), over 12 months under laboratory and field conditions. In both approaches, the fungicides were applied to the same loamy soil as a formulated mixture at several concentrations. We determined total DMX and EPX concentrations in the soil using exhaustive extraction, their environmental availability using mild extraction, and their bioavailability through internal concentrations in exposed earthworms. The initial fungicide application appeared as much better controlled in terms of dose and homogeneity in the laboratory than in the field. One year after application, a similar dissipation rate was observed between the laboratory and field experiments (ca 80\% and 60\% for DMX and EPX, respectively). Similarly, the ratio of available/total concentrations in soil displayed the same trend whatever the duration and the conditions (field or lab), EPX being more available than DMX. Finally, the environmental bioavailability of the two fungicides to earthworms was heterogeneous in the field, but, in the laboratory, the bioaccumulation was evidenced to be dose-dependent only for DMX. Our findings suggest that the actual fate of the two considered fungicides in the environment is consistent with the one determined in the laboratory, although the conditions differed (e.g., presence of vegetation, endogeic earthworm species). This study allowed better understanding of the fate of the two considered active substances in the soil and underlined the need for more research dedicated to the link between environmental and toxicological bioavailability.
\end{abstract}

Keywords: soil; ecotoxicology; pesticide; bioavailability; fate; exposure

\footnotetext{
${ }^{1}$ present address: joel.amosse@gmail.com

2 present address: sylvain.bart@york.ac.uk
} 


\section{Introduction}

About 2.5 million tons of pesticides with various modes of action are used yearly over vast areas worldwide (Zhang et al. 2011). Once applied, pesticides are subject to physical, chemical and biological dissipation processes including volatilization, adsorption, leaching and degradation. A fraction of applied pesticides remaining in the topsoil could be absorbed by living organisms, potentially generating ecotoxicological effects. This risk has been conceptualized through bioavailability, where the bioavailable fraction is the amount of a compound that is freely available and able to cross organisms' cell membrane from the soil where the organisms live at a given time, and thus enter the food chain (Semple et al. 2004). More practically, bioavailability can be described in three steps: (1) environmental availability (or soil offer) related to the potential of a compound to interact with an organism; (2) environmental bioavailability which is the uptake of the compound by the organism; and, finally (3) the toxicological bioavailability corresponding to the effect of the compound on the organism (Lanno et al. 2004; Harmsen 2007). Current methods used to assess the environmental availability and bioavailability include determining the concentration of the chemical in the soil, following a mild extraction and measuring the chemical concentration in the organism, respectively (ISO 17402 2008). Pesticide characteristics (e.g. polarity, solubility in water) influence the available concentrations in soils and the one measured in soil organisms. However, parameters such as particle distribution, organic matter content, their association into soil structure or climatic conditions (Chaplain et al. 2011), as well as the lifestyle of the exposed organisms (e.g. activity, feeding behaviour), also play a role. Pesticide concentrations in different environmental compartments can thus evolve in time and space, being subject to several factors interacting at various temporal and spatial scales (Harmsen 2007).

The fate of pesticides in soil under field conditions is often assessed through modelling, based on data from laboratory experiments that use homogenized soil and controlled incubation conditions. The representativeness and thus the relevance of such experiments is questionable due to soil heterogeneity (McDonald et al. 2006), vegetation cover (Zhao et al. 2003) and climatic variations (Chai et al. 2013) that occur under field conditions. Among the few studies (about 12 studies) performed under field and laboratory conditions with the same soils, pesticide persistence and/or sorption on soil constituents was found to be different. For instance, Ahmad et al. (2003) observed lower clopyralyd persistence in the laboratory than in the field due to differences in temperature, soil water content, shading and plant cover. In constrast, pesticide persistence was reported to be lower under field conditions in other studies (Herrero-Hernández et al. 2015; Karlsson et al. 2016). HerreroHernandez et al. (2015) mainly attributed this difference to the leaching of the pesticide to deeper soil. Karlsson et al. (2016) hypothesized and tested various reasons, such as extraction efficiency, losses from spray drift, interception and leaching to deeper horizons, but none of those processes could explain the discrepancy. The authors finally hypothesized (but not demonstrated) differences and dynamics in soil temperature, soil water content, plant uptake and stimulated degradation in the rhizosphere. Beulke et al. (2000) suggested that laboratory studies overestimated the persistence of pesticides by a factor of more than 1.25 in $44 \%$ of casestudies because of the above-mentioned parameters, as well as the occurrence of extra phenomena unlikely to take place in laboratory conditions (volatilization, wind erosion, photodegradation, leaching). The difference between field and laboratory may also vary depending on the studied pesticide: in Di et al. (1998), the persistence in topsoil was rather similar for chlorpyrifos, chlorthal dimethyl and promethryne, higher in the field than in the laboratory for fenamiphos, metalaxyl (because of leaching) and linuron but lower for metribuzin and propyzamide. In the same way, laboratory experiments using pure solutions of pesticides may lead to an underestimation of the pesticide sorption compared with field conditions, where formulated pesticides are applied (Cryer 2005). Overall, a tiered lab-to-field approach may be necessary to efficiently predict the fate of pesticides in the environment, whereas modelling is often based on laboratory results only (Beulke et al. 2000).

Pesticide risk assessment procedures include tests on non-target soil organisms such as collembolan, acari and earthworms. However, for soil invertebrates, little information is available on the extent to which data on pesticide effects from higher-tier tests using semi-field (e.g. terrestrial model ecosystems) and field conditions can be compared with laboratory data. In a review, Jänsch et al. (2006) found that, for 61 of the 71 pesticides for which data were available, this mismatch was due to different taxonomic composition between conditions, but also to a lack of information about the concentrations at which chronic toxicity could occur. Furthermore, most of the studies did not provide any information on pesticide availability, bioavailability or even fate in the soil 
(Jänsch et al. 2006). In a more recent review, laboratory studies were considered to provide opportunities to limit the number of variables potentially affecting the outcome of bioaccumulation assessments, but the importance of tiered testing approaches was recognized (Hoke et al. 2015). The same review described the bioavailable fraction as "the fraction of greatest importance when conducting terrestrial exposure studies". They also stated that "field studies may be necessary to benchmark the accuracy of these estimates of bioavailability".

Among living soil organisms, earthworms are some of the most sensitive soil taxa to chemicals due to their soft bodies, feeding habit (e.g. soil feeder) and the huge quantity of soil they ingest (e.g. about several tons per hectare, Lavelle 1996). They are recognized as bioindicators of soil health, quality and functioning (Paoletti 1999). Moreover, they are involved in key soil processes such as organic matter degradation and soil structure dynamics (Lavelle 1996).

To our knowledge, the link between pesticide use, available concentrations and internal concentrations in earthworms has never been explored simultaneously under laboratory and field conditions over relatively long periods such as several months. The aim of this study was to evaluate over 12-month laboratory and field experiments, (i) dissipation (in terms of total contents), (ii) environmental availability and (iii) bioavailability to earthworms of two active substances present in a formulated mixture. The commercial formulation was applied at three doses in the laboratory and two doses under field conditions. The higher dose, selected to maximize the processes, was modulated in field and laboratory conditions according to the lethal concentration. In the laboratory, the effect of the earthworms (and the organic matter added for feeding) on pesticide environmental availability and the effect of the applied dose on environmental bioavailability were also examined. The selected commercial formulation of a fungicide, containing dimoxystrobin (DMX) and epoxiconazole (EPX), was chosen for its common use in Europe on cereal crops. According to the PPDB database (2020), which retranscribes information from European EFSA dossiers, these active substances differ notably in their persistence in the field with dissipation half-life ( $\mathrm{DT}_{50}$ ) of 23 and 120-days for DMX and EPX, respectively. The persistence of the two molecules differs to a lesser extent in the laboratory with $\mathrm{DT}_{50}$ of 210 and 354-days for DMX and EPX, respectively. Two common species of earthworms were selected for our laboratory and field experiments: Aporrectodea caliginosa (Savigny, 1826) and Aporrectodea icterica (Savigny, 1826), respectively.

\section{Material and methods}

\section{Fungicides}

Epoxiconazole (EPX, CAS 133855-98-8, (2RS,3SR)-1-[3-(2-chlorophenyl)-2,3-epoxy-2-(4fluorophenyl)propyl]-1H-1,2,4-triazole) is a triazole fungicide acting as a sterol biosynthesis inhibitor with preventative and curative action. Dimoxystrobin (DMX, CAS 149961-52-4, (E)-2-(methoxyimino)- $N$-methyl-2[a-(2,5-xylyloxy)-o-tolyl]acetamide) is a stobilurin fungicide acting as a respiration inhibitor with protectant, curative and translaminar action. According to the PPDB database (2020), both compounds are relatively hydrophobic and poorly soluble in water $\left(\log K_{\text {ow }} 3.59\right.$ and 3.3, water solubility $4.3 \mathrm{mg} / \mathrm{L}$ and $7.1 \mathrm{mg} / \mathrm{L}$ for DMX and EPX, respectively). They were used in the field and laboratory experiments in the formulated mixture Swing® Gold (BASF Agro SAS), which contains 133 g/L DMX and 50 g/L EPX.

\section{Field experiment}

The field experiment was set up in a meadow where earthworms were abundant $\left(>200\right.$ individuals $\left./ \mathrm{m}^{2}\right)$, as recommended by the ISO standard method for earthworm field studies (ISO 11268-3 2014). The initial earthworm density and earthworm community were determined from ten sampling points randomly selected. The sampling of each sampling point and the earthworm identification methods are described in Amosssé et al. (2018). The most abundant species was Allolobophora icterica (mean of $180.6 \mathrm{ind} / \mathrm{m}^{2}$ ), followed by Lumbricus terrestris (mean of $32.5 \mathrm{ind} / \mathrm{m}^{2}$ ), Aporrectodea giardi (mean of $23.8 \mathrm{ind} / \mathrm{m}^{2}$ ), Lumbricus castaneus (mean of 20.6 ind $/ \mathrm{m}^{2}$ ), Aporrectodea caliginosa (mean of $10.6 \mathrm{ind} / \mathrm{m}^{2}$ ), Allolobophora chlorotica (mean of $6.9 \mathrm{ind} / \mathrm{m}^{2}$ ), Aporrectodea longa (mean of $6.3 \mathrm{ind} / \mathrm{m}^{2}$ ) and three others not exceeding a mean of $5 \mathrm{ind} / \mathrm{m}^{2}$. This meadow, 
located in Versailles (France), had not received pesticides for more than 20 years. The main characterictics of the soil (Luvisol, FAO soil classification) were as follows: loam texture (29\% sand, $48 \%$ silt and 23\% clay), pH 7.5, soil bulk density 1.29 , organic matter $32.6 \mathrm{~g} / \mathrm{kg}, \mathrm{C} / \mathrm{N} 12.7, \mathrm{CaCO}_{3} 23.3 \mathrm{~g} / \mathrm{kg}$, water holding capacity WHC 0.41 $\mathrm{g} / \mathrm{g}$ (see Bart et al. 2017 for more details). Four replicate plots $(10 \mathrm{~m} \mathrm{x} 10 \mathrm{~m})$ of each fungicide treatment were randomly located and separated by $6 \mathrm{~m}$ buffer strips. After cutting the vegetation as short as possible, the Swing® Gold formulation was applied with manual sprayers, using $8 \mathrm{~L}$ of diluted solution per plot (Amossé et al. 2018). The application on the plots was performed at the recommended dose (replicates D1-1 to D1-4), tenfold the recommended dose (D10-1 to D10-4), and control plots were not treated. The recommended dose corresponds to 199.5 and $75 \mathrm{~g} /$ ha of DMX and EPX, respectively. Considering that the active compounds of the Swing ${ }^{\circledR}$ Gold formulation are almost always found in the top $10 \mathrm{~cm}$ of soil (McDonald et al. 2013; Chabauty et al. 2016), the recommended dose D1 corresponded to 150 and $60 \mu \mathrm{g} / \mathrm{kg}$ dry soil of DMX and EPX, respectively (thus D10 to 1500 and $600 \mu \mathrm{g} / \mathrm{kg}$ dry soil of DMX and EPX, respectively). Soil (three cores per plot, $5 \mathrm{~cm}$ diameter and $10 \mathrm{~cm}$ depth, were mixed to obtain a composite sample submitted to analysis) and earthworms Aporrectodea icterica (three adults/sub-adults per plots) were sampled before application and 5, 26, 209 and 363 days after the application. This endogeic species of earthworm was chosen because it was the most abundant species found at the experimental site. To evaluate initial leaching of the active substances, extra soil samples were taken at 9 days after contamination at $0-10 \mathrm{~cm}, 10-20 \mathrm{~cm}$ and $20-30 \mathrm{~cm}$ in four of the plots (two D1 plots and two D10 plots).

\section{Laboratory study}

Laboratory studies were performed using the same soil as in the field experiment. The soil was collected from the top 0-20 cm one month before starting the experiment, air-dried, ground and sieved at $2 \mathrm{~mm}$ before being stored at $20^{\circ} \mathrm{C}$. The recommended dose considered here was defined as previously, i.e. 150 and $60 \mu \mathrm{g} / \mathrm{kg}$ dry soil of DMX and EPX, respectively. The laboratory experiments were performed with Swing® Gold at one third the recommended dose (D0.33), the recommended dose (D1) and three-times this dose (D3); untreated soils (control) were also included. The D10 dose used in the field was not tested in the laboratory as Swing ${ }^{\circledR}$ Gold presented a lethal concentration $\left(\mathrm{LC}_{50}\right)$ for the studied earthworm corresponding to 6.3 times the recommended dose (Bart el al. 2017). As we planned to assess the internal concentration of living earthworm, we thus limited the highest dose to D3. Furthermore, we added the dose D0.33 under laboratory conditions to evaluate the fate of the fungicides under controlled conditions. For each tested concentration, the soil was spiked by mixing dry soil with aqueous dilutions of Swing® Gold in tap water and the soil moisture was adjusted concomitantly at $70 \%$ of the Water Holding Capacity (WHC). The equivalent of $400 \mathrm{~g}$ dry soil was placed in $1 \mathrm{~L}$ plastic vessels with a removable perforated cover for gas exchange. The moisture of each vessel was checked every 14 days by weighing vessels and adjusted if necessary. All the vessels were stored in a climate room $\left(15 \pm 1{ }^{\circ} \mathrm{C}, 24 \mathrm{~h}\right.$ darkness). To evaluate i) the persistence and the environmental availability of DMX and EPX in soil over time and ii) the link between environmental availability and bioavailability of DMX and EPX for earthworms, two groups of vessels were performed and four replicates were used for each group and modality.

The first group corresponded to the vessels containing only soil. It was sampled for analysis $0,28,56,84,247$, 275,303 and 366 days after spiking.

The second group included the vessels with earthworms. The chosen earthworm species was a dominant earthworm species in cultivated fields in temperate areas (Bart et al. 2018), Aporrectodea caliginosa. It is also an endogeic species, but relatively easy to breed in the lab (Bart et al. 2018), contrarily to A. icterica. Moreover, although A. caliginosa was present in the field site, the abundance was too low (i.e., mean of 10.6 individuals $/ \mathrm{m}^{2}$, compared to A. icterica at 180.6 individuals $/ \mathrm{m}^{2}$ ) to collect enough individuals for internal concentration measurements. Finally, A. caliginosa and A. icterica are ecologically similar, with similar length, pigmentation and habitat, both living in the first $20 \mathrm{~cm}$ of soil (Bouché, 1972). One earthworm (reared in the laboratory) was added per vessel and the equivalent of $3 \mathrm{~g}$ dry horse dung (adjusted to $70 \%$ of its WHC) was added by mixing with the soil every 14 days. The horse dung, necessary as a food source for the earthworms, was previously frozen and defrosted twice and then milled $(<1 \mathrm{~mm})$ (Lowe and Butt, 2005). Earthworms were 
exposed for 28,56 or 84 days before being sampled for analysis. The earthworms exposed for 56 and 84 days were transferred to new vessels (prepared at day 0 ) every 28 days (i.e. one transfer for individuals exposed for 56 days and two transfers for individuals exposed for 84 days). This procedure was necessary to avoid soil compaction and excessive organic matter enrichment that could acidify the soil, which could lead to unsuitable conditions for earthworms (Bart et al. 2018). The soil from the second group of vessels was also sampled at days 28,56 and 84.

\section{Chemical analysis \\ Chemicals}

The EPX and DMX used as analytical standards (Pestanal grade, ie 99.0\% and 99.9\%, respectively), hydroxypropyl- $\beta$-cyclodextrin (HPCD), $\mathrm{Na}_{2} \mathrm{SO}_{4}, \mathrm{NaCl}, \mathrm{CaCl}_{2}$, formic acid and acetic acid were purchased from Sigma-Aldrich. All organic solvents of analytical grade were purchased from Carlo-Erba, and LC-grade water was obtained through a Milli-Q system (Millipore).

\section{Soil extraction}

The soil sampled through three cores from the field experiment was mixed, homogenized, removing the main pieces of vegetation, and then sieved at $5 \mathrm{~mm}$. For both field and laboratory experiments, an aliquot of sampled soil was immediately analysed to evaluate the environmental availability and a complementary sample was stored at $-40^{\circ} \mathrm{C}$ to evaluate the total DMX and EPX contents.

To evaluate the environmental availability of DMX and EPX in soil, an extraction was performed according to Nélieu et al. (2016). Briefly, $4 \mathrm{~g}$ of wet soil was placed in a 50-mL polypropylene tube (Falcon BD) and $9 \mathrm{~mL}$ of $50 \mathrm{mM}(70 \mathrm{~g} / \mathrm{L})$ hydroxypropyl- $\beta$-cyclodextrin aqueous solution was added. Tubes were shaken for $17 \mathrm{~h}$ on a reciprocating shaker at $17 \mathrm{rpm}$ at ambient temperature and then centrifuged at $10,000 \mathrm{~g}$ and $4{ }^{\circ} \mathrm{C}$ for $10 \mathrm{~min}$ (Beckman Coulter Allegra X-15R). The matrix effect was evaluated at less than $15 \%$. Analyses were performed within $24 \mathrm{~h}$ after preparation.

To evaluate the total content of DMX and EPX, freeze-dried soil was manually ground with a mortar. Triplicate soil subsamples of $5 \mathrm{~g}$ were placed in $50-\mathrm{mL}$ polypropylene tubes (Falcon $\mathrm{BD}$ ) and $10 \mathrm{~mL}$ of methanol was added to each tube. The tubes were shaken on an orbital shaker $(10 \mathrm{~min}, 300 \mathrm{rpm})$ and sonicated for $20 \mathrm{~min}$, before being centrifuged for $10 \mathrm{~min}$ at $1300 \mathrm{~g}$ and $20^{\circ} \mathrm{C}$. After collecting $7 \mathrm{~mL}$ of supernatant, the soil was again extracted with $10 \mathrm{~mL}$ of methanol with the same procedure. Then, $10 \mathrm{~mL}$ of supernatant was collected and mixed with the first extract. The D0.33, D1 and D3 samples were analysed without further preparation. For D10, an aliquot was diluted by a factor of 10 using a water/acetonitrile mixture $(80: 20, \mathrm{v} / \mathrm{v})$ prior to analysis, to allow these samples to be within the calibration curve range. The samples containing low concentrations (less than 2 $\mu \mathrm{g} / \mathrm{kg}$, ie pre-application and controls) were further diluted by $200 \mathrm{~mL}$ of water then purified and concentrated by solid phase extraction on HR-XA cartridges ( $500 \mathrm{mg}$, Macherey-Nagel) preconditioned successively by $5 \mathrm{~mL}$ of methanol, acetonitrile and water. After percolation of the diluted extracts, cartridges were rinsed with $5 \mathrm{~mL}$ of water, dried under vacuum and eluted in $6 \mathrm{~mL}$ of a 95:5 (v/v) acetonitrile/formic acid mixture. Samples were then evaporated under a $\mathrm{N}_{2}$ stream, dissolved in $3 \mathrm{~mL}$ of 8:2(v/v) water/acetonitrile and analysed.

\section{Earthworm extraction}

After sampling, earthworms were relieved from their gut contents for $48 \mathrm{~h}$ before being frozen at $-80^{\circ} \mathrm{C}$. Total DMX and EPX measurements in earthworms were measured using a method based on that described by Nélieu et al. (2016). Frozen earthworms from the field experiment were cut and pieces were divided into three $2 \mathrm{~mL}$ microtubes (Sarstedt). These triplicate subsamples (ca $1 \mathrm{~g} /$ tube) were homogenized using a FastPrep®-24 (MP Biomedicals) in $0.5 \mathrm{~mL}$ of Milli-Q water with a ceramic sphere, by two $20 \mathrm{~s}$ cycles at $6 \mathrm{~m} / \mathrm{s}$. Homogenization was similar for each single earthworm issuing from laboratory studies $(0.5-0.8 \mathrm{~g} /$ tube $)$. The homogenate was 
then transferred to a $15-\mathrm{mL}$ polypropylene tube (Falcon BD), with three times $0.5 \mathrm{~mL}$ water used to rinse the 2 $\mathrm{mL}$ tube. DMX and EPX extractions were then performed by adding $4 \mathrm{~mL}$ acetonitrile in the tube, shaking on an orbital shaker (Ika KS 501, at $300 \mathrm{rpm}$ for $10 \mathrm{~min}$ ) and sonicating for $15 \mathrm{~min}$. Then, $2 \mathrm{~mL}$ of water, $1.6 \mathrm{~g}$ $\mathrm{Na}_{2} \mathrm{SO}_{4}$ and $0.4 \mathrm{~g} \mathrm{NaCl}$ were added to carry out a QuEChERS purification. The tube was vigorously shaken and centrifuged for $10 \mathrm{~min}$ at $10,900 \mathrm{~g}$ and $4{ }^{\circ} \mathrm{C}$. The upper organic layer was collected, placed at least $2 \mathrm{~h}$ at $-40{ }^{\circ} \mathrm{C}$ and centrifuged for $10 \mathrm{~min}$ at $10,900 \mathrm{~g}$ and $4{ }^{\circ} \mathrm{C}$. A $3 \mathrm{~mL}$ fraction of the supernatant was dried through $2-\mathrm{g}$ $\mathrm{Na}_{2} \mathrm{SO}_{4}$ addition and centrifugation $\left(10 \mathrm{~min}, 10,900 \mathrm{~g}, 4{ }^{\circ} \mathrm{C}\right)$. A $1 \mathrm{~mL}$ aliquot of supernatant was then evaporated to dryness under a $\mathrm{N}_{2}$ stream and redissolved in $0.5 \mathrm{~mL}$ chloroform. This extract was further purified on 500-mg Florisil cartridges (preconditioned successively by $2 \mathrm{~mL}$ of methanol, acetone and chloroform). Elution was performed by $5 \mathrm{~mL}$ of a 9:1 (v/v) chloroform/acetone mixture. After evaporation under a $\mathrm{N}_{2}$ stream, the residue was dissolved in $1 \mathrm{~mL}$ of 8:2(v/v) water/acetonitrile and analysed by liquid chromatography-mass spectrometry.

\section{Analysis by liquid chromatography-mass spectrometry}

Analyses were performed on an ultra-high performance liquid chromatograph (Acquity UPLC, Waters) coupled through an electrospray interface to a triple quadrupole mass spectrometer (TQD, Waters). The analytical conditions were as described by Nélieu et al. (2016), except the UPLC gradient (95/5 to 45/55 of water/acetonitrile, each containing $0.1 \%$ acetic acid) and the introduction of conditions to detect DMX (cone voltage $23 \mathrm{~V}$, MRM transitions 327>205 at $10 \mathrm{eV}$ for quantitation and 327>116 at $17 \mathrm{eV}$ for confirmation). In soil, the LOD (limit of detection, according to a signal-to-noise ratio of 3) was $0.03 \mu \mathrm{g} / \mathrm{kg}$ and $0.05 \mu \mathrm{g} / \mathrm{kg}$ for DMX and EPX, respectively, and the LOQ (limit of quantification, validated by accuracy profile methodology) was $0.28 \mu \mathrm{g} / \mathrm{kg}$ and $0.22 \mu \mathrm{g} / \mathrm{kg}$ for DMX and EPX, respectively. In the earthworms, the LOQ (according to a signal-to-noise ratio of 7) was $0.02 \mu \mathrm{g} / \mathrm{g}$ for DMX and $0.05 \mu \mathrm{g} / \mathrm{g}$ for EPX.

\section{Adsorption experiments}

Adsorption experiments were performed according to OECD guideline 106 (OECD, 2000), using Swing® Gold and a mixture of DMX and EPX in pure solution (water with $2 \%$ acetonitrile). Duplicate dry soil samples of 1.5 $\mathrm{g}$ were equilibrated for $24 \mathrm{~h}$ in borosilicate tubes with $15 \mathrm{~mL}$ of $\mathrm{CaCl}_{2} 10 \mathrm{mM}$ solution, before spiking at concentrations ranging from 5.8 to $250 \mu \mathrm{g} / \mathrm{L}$ for DMX and from 2.3 to $100 \mu \mathrm{g} / \mathrm{L}$ for EPX. After 24-h of agitation, the tubes were centrifuged $(5000 \mathrm{~g}, 10 \mathrm{~min})$ and the supernatant analysed. Adsorption isotherms were described according to the Freundlich model as follows:

$K_{\mathrm{f}}=$ Qads $/ \mathrm{Ce}^{1 / \mathrm{n}}$

where Qads (mg/kg) is the amount of adsorbed fungicide in soil at equilibrium concentration, Ce $(\mathrm{mg} / \mathrm{L})$ is fungicide concentration in supernatant solution, and $\mathrm{K}_{\mathrm{f}}$ and $\mathrm{n}$ are Freundlich empirical adsorption coefficients.

\section{Data analysis}

Data were represented by the mean \pm standard deviation, or the slope \pm confidence interval at $p=0.05$ in the case of linear regressions. Fungicide dissipation in the field experiment was tested with the non-parametric Mann and Whitney test. For bioaccumulation factors in the laboratory study, non-parametric tests (Kruskal-Wallis test followed by a multiple comparison) were used. In the laboratory study, the dissipation kinetics were fitted according to the FOCUS recommendations (FOCUS 2006), using R (package kinfit), to select the best kinetic model according to the goodness of fit. To test the influence of presence/absence of earthworms and horse dung on the linear relationship between total and available concentrations of DMX end EPX, we used linear models and tested the interactions with the group "presence/absence". 


\section{Results and discussion}

\section{Dissipation of the two fungicides \\ Field experiment}

Before their application, the concentrations of both fungicides DMX and EPX were below limit of detection in the soil where the experiment took place. They remained under the limit of quantification in the soil sampled in control plots all throughout the experiment.
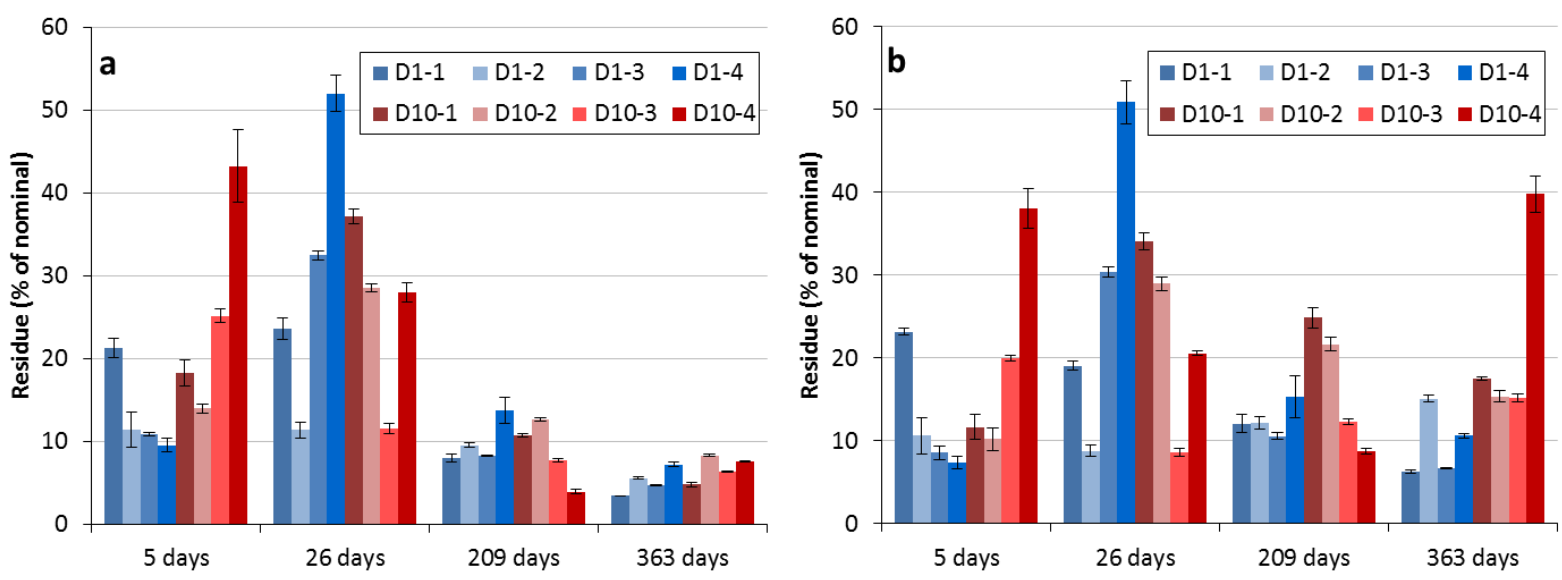

Fig. 1 Dimoxystrobin (a) and epoxiconazole (b) residues under field conditions in the $0-10 \mathrm{~cm}$ soil layer, in $\%$ of the nominal dose (mean and standard deviation of analytical measurements, $n=3$ )

Five days after the application of Swing ${ }^{\circledR}$ Gold, the total DMX and EPX contents in the soil were found to be far below the applied concentrations (Figure 1). The maximum concentrations were ca $43 \%$ and $38 \%$ of the applied dose for DMX and EPX, respectively (in D10-4, see Figure 1). A minor part of this difference could have been due to leaching since we found 2.2 to $6.3 \%$ and 1.8 to $4.8 \%$ for DMX and EPX, respectively, between 10 and 30 $\mathrm{cm}$ deep (at day 9). However, the main reason for the initial low concentration in the $0-10 \mathrm{~cm}$ soil layer was certainly the vegetation cover that acted as a barrier limiting the fungicide from migrating into the soil. The foliage of a short cut pasture also intercepted as high as $90 \%$ of an herbicide deposit in another study (Ahmad et al. 2003). A large heterogeneity was observed between replicates, with minimal concentrations 2.2 to 5 times lower than the maximal concentration. For example, in D10 plots, the EPX concentration was estimated as $61 \pm$ $8 \mu \mathrm{g} / \mathrm{kg}$ and $228 \pm 14 \mu \mathrm{g} / \mathrm{kg}$ in D10-2 and D10-4 plots, respectively (nominal $600 \mu \mathrm{g} / \mathrm{kg}$ ). Considering the four replicate plots, the mean percentages versus nominal concentrations appeared as lower at D1 than at D10 (figure S1), but the difference was not significant (Mann and Whitney test). At D1 the means ( \pm standard deviation) corresponded to $13.3 \pm 5.4 \%$ and $12.4 \pm 7.3 \%$ of nominal DMX and EPX, respectively, whereas at D10 they were $25.2 \pm 12.9 \%$ and $19.9 \pm 12.8 \%$ for DMX and EPX, respectively. The heterogeneity could not be attributed to the analytical determination, as shown by the analytical standard deviations in Figure 1. Similarly, the discrepancy between nominal and observed fungicide concentrations could not be due to an analytical problem as extraction yields were estimated as $93-110 \%$ with a low matrix effect due to electrospray ionization. Furthermore, even with a maximal storage time of 4 months between soil sampling and analysis, the yields of the analytical method did not decrease. However, the heterogeneity of the measures could result from an uneven application of the fungicide on the plots. This uneven application could both result from (1) irregular spraying and (2) since the vegetation was not completely homogeneous on the experimental site, it consequently unevenly intercepted the fungicides. The collection and mixing of three soil cores did not seem to be able to counteract these factors.

Twenty six days after the application of Swing® Gold, the DMX and EPX concentrations in the soil increased significantly (Mann and Whitney test) in half of the plots (Figure 1): D1-3, D1-4, D10-1 and D10-2 for both 
active substances and (slightly even if it was significant) D1-1 for DMX only. However, no significant change in concentration was observed in the plot D1-2 and the fungicides concentration in soil significantly decreased in D10-3 and D10-4 (and D1-1 for EPX only). The increases were interpreted as a transfer from the vegetation cover to the soil. However, the vegetation was not completely homogeneous in the experimental site, and this fact could explain the difference between the various replicates. This transfer reached up to a factor of 7, in D1-4 where EPX increased from $7.3 \pm 0.8 \%$ at day 5 to $50.9 \pm 2.6 \%$ at day 26 . Considering all four replicate plots, the means increased between days 5 and 26, from approximately $12-25 \%$ to $23-30 \%$, but the change was not significant due to the high inter-plot variability (Figure S1). The changes resulted at day 26 in residues varying between 11 and $52 \%$ of the DMX nominal dose and in 8.6 and 51\% of the EPX nominal dose. An important difference between the minimum and maximum values was also observed for the days 209 and 363, mostly for EPX. For instance at day 363, "only" a factor 2.4 differentiates the minimal and maximal DMX residue percentage (3.5\% vs $8.3 \%$ ), but this factor reaches up 6.4 and the case of DMX (6.2\% vs $39.8 \%)$. This heterogeneity led to high inter-plot standard deviations (Figure S1). Six months (209 days) and 1 year (363 days) after Swing ${ }^{\circledR}$ Gold application, a decrease in DMX concentration was observed. This DMX dissipation was significant between days 26 and 363, but not between days 26 and 209 (Mann and Whitney test). However, if data were considered plot per plot, all DMX concentrations significantly decreased between days 26 and 209. There was no significant dissipation of EPX in any condition, and not even a tendency was observed for EPX at D10 (Figure S1). However, considering the EPX change plot per plot, a significant EPX dissipation after 26 days was observed in all plots except D1-2, D10-3 and D10-4, where EPX concentrations were stable or even increased over time. These apparent increases could be due to high field heterogeneity which caused high fungicide adsorption in localised spots. The variability in the field dissipation of pesticides was previously observed by other authors and attributed to spatial variation in soil and/or microbial properties (Bending et al. 2006).

The persistence of both active substances was higher in this experiment than expected from data reported in the literature. After 1 year, a value below LOQ and ca. 12\% was expected for DMX and EPX respectively, according to the $\mathrm{DT}_{50}$ (PPDB 2020) in the field and assuming first order dissipation kinetics. However, after our 1 year experiment, we found approximately $13-48 \%$ and 20-53\% of DMX and EPX remaining, respectively (considering as initial value the maximal concentration at 5 or 26 days).

\section{Laboratory study and comparison with the field experiment}

In contrast to the results obtained from the field experiment, the concentrations of the two active substances in the laboratory experiment evaluated 1 day after soil contamination were close to the nominal concentration: $101.9 \pm 13.4 \%$ and $98.1 \pm 16.7 \%$ for DMX and EPX, respectively. In addition, the heterogeneity between replicates remained low, with standard deviations rarely exceeding $5 \%$ (for $n=4$ ). The absence of vegetal cover and the soil mixing, which homogenized its properties and the contamination, are the obvious factors explaining these results. Such factors were already underlined by various studies (Beulke et al. 2000; Wu et al. 2015; Karas et al. 2018; de Santo et al. 2019).

After 84 days of incubation under all the studied conditions in the laboratory, a similar fungicide dissipation level was observed, reaching ca $40 \%$ of the applied concentration (Figure S2). Overall, neither the initial concentration nor the presence of earthworm and horse dung had an influence on the dissipated fraction. The absence of a concentration effect on dissipation is not consistent with observations on other pesticides such as azoxystrobin, chlorpyrifos, tebuconazole or isoproturon (Herrero-Hernandez et al. 2015; Chai et al. 2013; Papadopoulou et al. 2016). For these active substances, previous studies found that the higher the concentration, the slower the dissipation. However, considering a maximal spiking of $1 \mathrm{mg} / \mathrm{kg}$ (thus limiting the impact on soil microbes of applied fungicides), the EPX dissipation was shown as not dependent on the dose (Neuwirthová et al. 2018). 

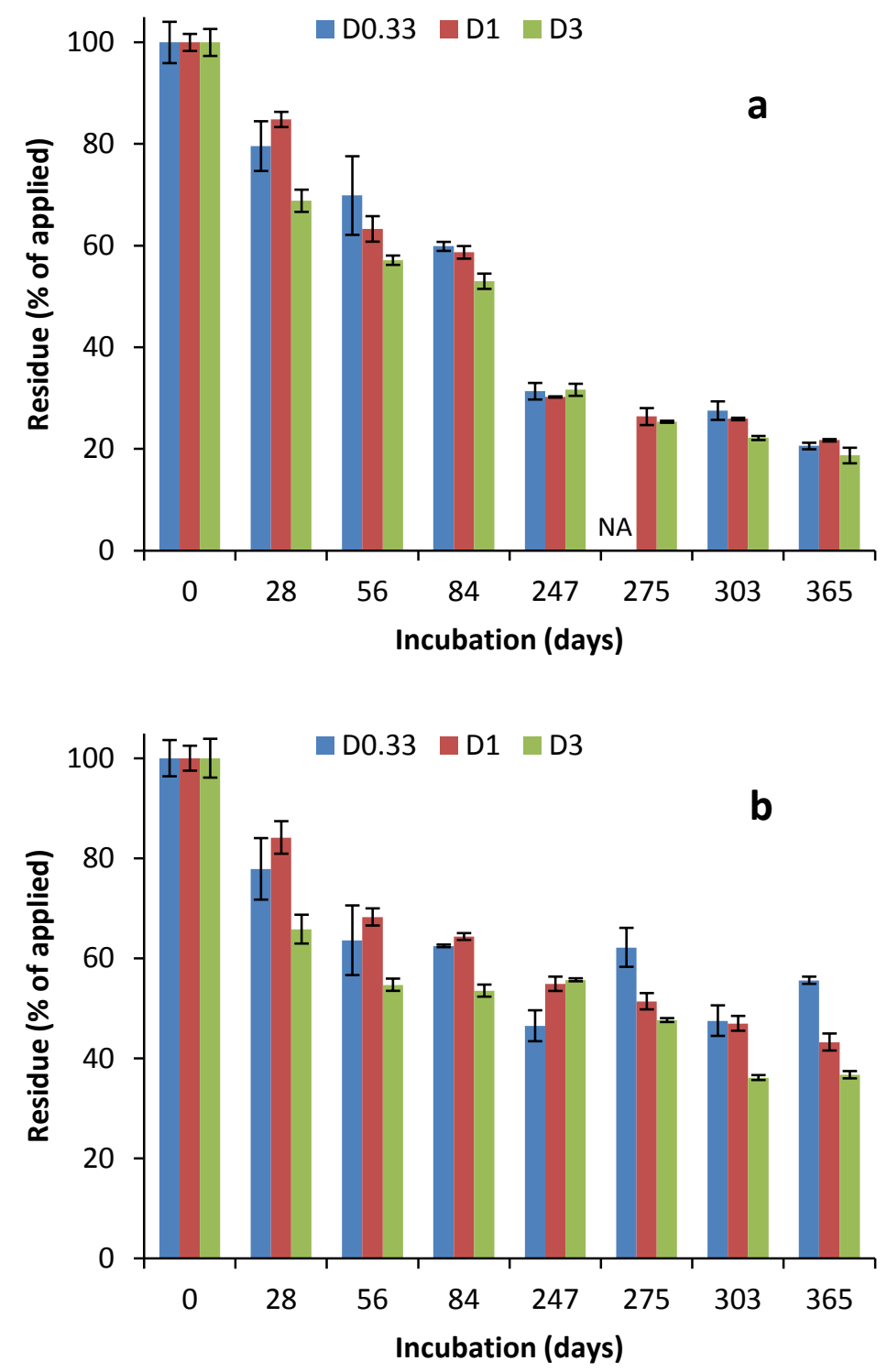

Fig. 2 Dimoxystrobin (a) and epoxiconazole (b) residues in soils, during laboratory studies without earthworms (mean and standard deviation of replicates, $n=4$; NA for not available)

In the present study, the dissipation kinetics of both active substances were quite similar over 84 days (Figures 2 and S2). However, their degradation behaviour was different when a longer incubation time was considered (Figure 2). DMX was degraded more than EPX after 1 year, reaching ca $20 \%$ of residues while ca $40 \%$ of EPX was still present. The half-lives were estimated as 94-135 and 153-301 days for DMX and EPX, respectively. After temperature and moisture normalisation according to FOCUS recommendations (FOCUS 2006), the $\mathrm{DT}_{50}$ shift to 108-156 and 177-348 days for DMX and EPX, respectively, i.e. on average 39 and 18\% quicker than expected from laboratory $\mathrm{DT}_{50}$ data available in the PPDB database. This trend was in striking contrast to that observed in the field experiment where active substance degradation was slower than that based on PPDB data. It is worth noting that the kinetics observed in our laboratory and field experiments in the same soil were quite similar. 


\section{Evaluation of environmental availability}

For all the studied conditions, regardless of time and conditions (laboratory or field), environmental availability was proportional to the total residues (Figure 3). Thus, although the fungicides degraded over time and conditions were not the same, an equivalent fraction of the tested pesticides remained available in the soil. The linear regressions explained $90.4 \%$ variability of EPX and $85.5 \%$ of DMX in field experiments, and 95.5 to $98.7 \%$ in laboratory experiments.
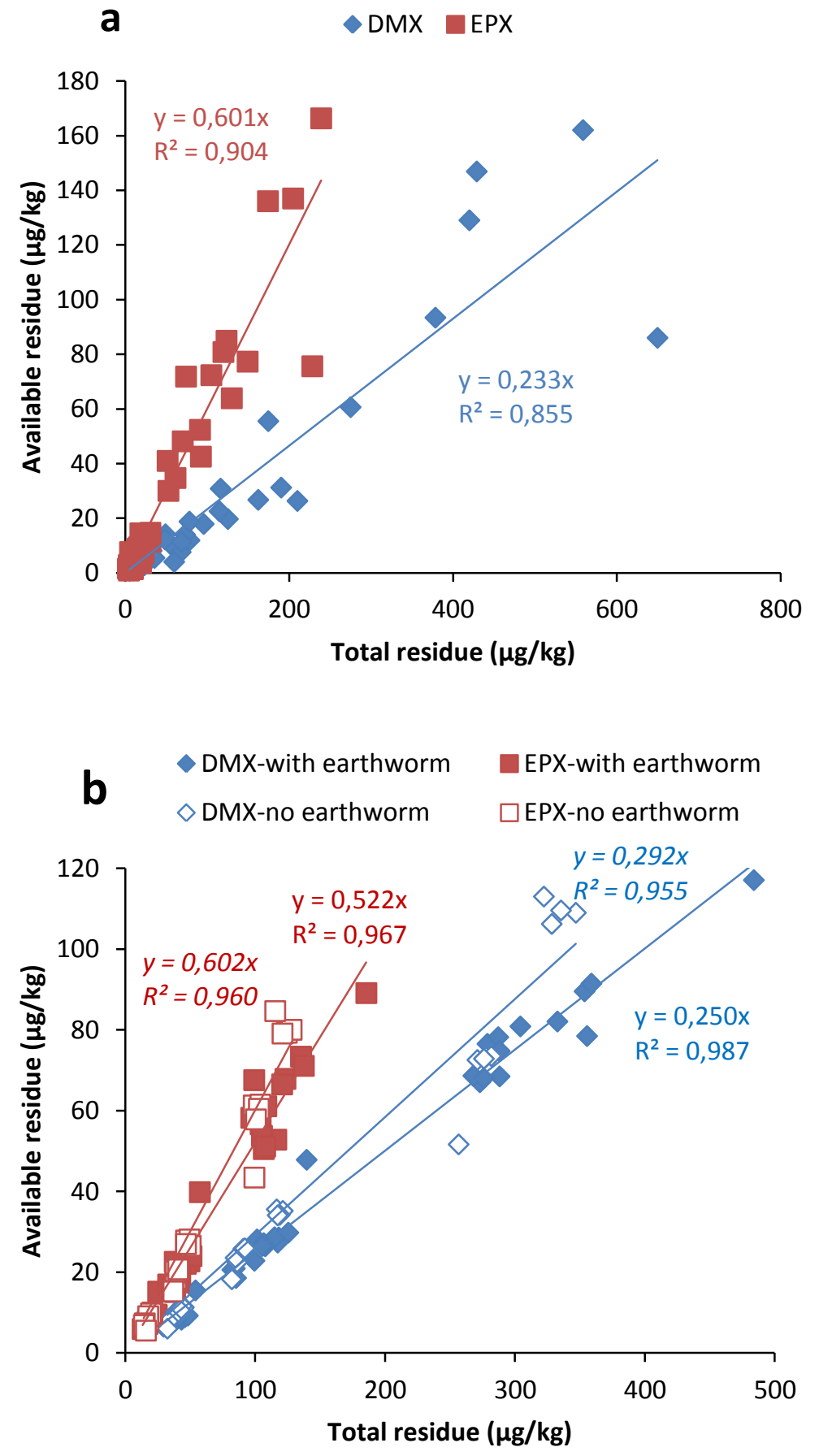

Fig. 3 Available fungicides in soil as a function of total residues: (a) field experiment, (b) laboratory study. DMX: Dimoxystrobin, EPX: Epoxiconazole 
DMX was less available than EPX in both lab and field conditions. According to the slopes shown in Figure 3a, in the field experiment, $23.3 \pm 2.4 \%$ of DMX was available versus $60.1 \pm 4.6 \%$ of EPX. The results from the lab experiment also showed a slight effect of the presence of earthworms and horse dung, which reduced the compound availability (Figure 3b). DMX availability shifted from $29.2 \pm 1.6 \%$ without earthworms and horse dung to $25.0 \pm 0.6 \%$ when they were present. EPX availability decreased from $60.2 \pm 3.1 \%$ to $52.2 \pm 2.0 \%$. The interaction test between variables of the linear model showed that this shift was only slightly significant for EPX $(p=0.053)$ but highly significant for DMX $(p<0.001)$. The decrease in availability when earthworms are present was previously observed (Bolan and Baskaran 1996; Shan et al. 2011). It was attributed to changes (1) in soil structure, by break down of some soil aggregates releasing silt and clay sorption sites and/or (2) in the nature of the soil organic matter increasing the abundance of functional groups able to engage interactions with the pollutants (Shan et al. 2011). This reduction could result from the impact of the horse dung that was necessary for earthworm maintenance during the experiment. This added organic matter probably participated in pesticide adsorption as was widely observed in other studies (Herrero-Hernandez et al. 2015; Gosh and Singh 2009). Indeed, we previously demonstrated that horse dung decreased the EPX availability (Nélieu et al. 2016).

Table 1: Freundlich adsorption coefficients for dimoxystrobin and epoxiconazole in pure and formulated solutions $\left(K_{f}\right.$ in $\left.m g^{(1-1 / n)} \cdot L^{1 / n} \cdot \mathrm{kg}^{-1}\right)$

\begin{tabular}{lll}
\hline & Dimoxystrobin & Epoxiconazole \\
\hline Data in PPDB & $\mathrm{K}_{\mathrm{f}}=9.6$ (range 0.58-18.62) & $\mathrm{K}_{\mathrm{f}}=12.18$ (range 4.79-21.78) \\
& $1 / \mathrm{n}=0.92$ (range 0.894-0.942) & $1 / \mathrm{n}=0.836$ (range 0.766-0.910) \\
& $\mathrm{K}_{\text {foc }}=486$ (range 195.8-935.3) & $\mathrm{K}_{\text {foc }}=1073$ (range 280-2647) \\
\hline Pure solution & $\mathrm{K}_{\mathrm{f}}=5.38 \pm 1.07$ & $\mathrm{~K}_{\mathrm{f}}=21.7 \pm 1.1$ \\
& $1 / \mathrm{n}=0.87 \pm 0.01$ & $1 / \mathrm{n}=0.85 \pm 0.01$ \\
& $\mathrm{~K}_{\text {foc }}=285$ & $\mathrm{~K}_{\text {foc }}=115$ \\
\hline Swing® Gold & $\mathrm{K}_{\mathrm{f}}=8.38 \pm 1.21$ & $\mathrm{~K}_{\mathrm{f}}=28.8 \pm 1.2$ \\
& $1 / \mathrm{n}$ not significant $(0.96 \pm 0.05)$ & $1 / \mathrm{n}=0.89 \pm 0.03$ \\
& $\mathrm{~K}_{\text {foc }}=444$ & $\mathrm{~K}_{\text {foc }}=153$ \\
\hline
\end{tabular}

The large difference in availability between DMX and EPX, observed both under field and laboratory conditions, was surprising based on their physicochemical properties, in particular their close hydrophobicity $\left(\log K_{\text {ow }} 3.59\right.$ and 3.3, respectively) and Freundlich adsorption coefficients $\left(K_{\mathrm{f}} 9.6\right.$ and 12.18, Table 1). We hypothesized that this unexpectedly sizeable difference could result either from a specificity of our soil (in texture or organic matter content), or from the use of the fungicide as a formulated solution, as formulating agents may affect the sorption of the pesticides. The adsorption of the two fungicides in our soil was thus determined using a pure solution and the formulated Swing ${ }^{\circledR}$ Gold (Table 1). The Freundlich adsorption coefficients obtained for DMX were three to four-fold lower than those for EPX. According to these data, DMX should have been retained to a significantly lesser extent than EPX, but this contradicted our findings for environmental availability. Anecdotally, we also found that the presence of formulating agents increased the $\mathrm{K}_{\mathrm{f}}$ by 56 and $33 \%$ for DMX and EPX, respectively (5.38 to 8.38 and 21.7 to $28.8 \mathrm{mg}^{(1-1 / \mathrm{n})} \cdot \mathrm{L}^{1 / \mathrm{n}} \cdot \mathrm{kg}^{-1}$ ). Thus, a higher sorption was observed with the formulated fungicide, as previously observed for metalaxyl or tebuconazole (Pose-Juan et al. 2010; Cadková et al. 2013). When compared with the data of EU dossiers and published in the PPDB database, our values were globally within the same range for DMX (except the parameter $1 / \mathrm{n}$ with Swing® Gold), whereas for EPX the $\mathrm{K}_{\mathrm{f}}$ was slightly higher and $\mathrm{K}_{\text {foc }}$ largely lower. To explain the difference in behaviour evaluated through environmental availability (DMX less available than EPX) and adsorption studies (DMX more available than EPX), two reasons can be hypothesized. First, a hysteresis phenomenon could occur, decreasing DMX desorption as previously observed for some other strobilurin fungicides (Reddy et al. 2013, Wu et al. 2016; Liu et al. 2018). The second hypothesis is based on potential interactions driving pesticides remobilisation from soil, independantly of their solubilisation. The HPCD used to study environmental availability is mostly efficient for establishing hydrophobic interactions and hydrogen bonds leading to inclusion in the hydrophobic cavity (Reid et al. 2000), whereas the $\mathrm{CaCl}_{2}$ used for the adsorption study engages ionic interactions (Harmsen 2007). Thus, 
our results may come from the interactions between soil constituents and the pesticide that relied more on ionic interactions for DMX than for EPX. This could occur because of the lateral chain in DMX, which presents polar groups and lone pairs (see structures, Figure S3). Indeed, Ghosh et al. (2009) suggested an interaction between the carbonyl group of azoxystrobin (also present in DMX) and the organic or mineral fraction of the soil.

\section{Environmental bioavailability: bioaccumulation in earthworms}

The fungicide residues found in the soil were compared with residues analysed in earthworms in the laboratory and field studies. Overall, the concentration in earthworms remained lower (DMX) or largely lower (EPX) than the total residues measured in the soil. The only exceptions were observed for DMX at the lowest tested dose, once during the field experiment (5 days after application in D1), and in most cases at D0.33 in the laboratory study. However, even in these cases, the bioaccumulation remained limited as the earthworm/soil ratio was still lower than 2 in any case.

During the field experiment, an early and transitory bioaccumulation of the tested active substances could have happened in some earthworms at D10, which induced the death of numerous anecic and endogeic earthworms (Amossé et al. 2018). This is in accordance with the $\mathrm{LC}_{50}$ of Swing® Gold for A. caliginosa, which is 6.3 times the recommended dose (Bart et al. 2017). However, the environmental bioavailability was measured only on earthworm individuals sampled alive. In the field experiment, no correlation was found between the fungicide concentration in earthworms and in soil, whether we considered the total or available fraction (Figure S4). This could be due to earthworm behaviour since the pesticide could limit their feeding activity and/or increase avoidance of the most polluted spots (Jager et al. 2005). However, after 1 month, A. icterica population (the sampled species) showed no significant change at D1 but decreased slightly at D10 (Amossé et al. 2018). Meanwhile, in the field, the A. caliginosa species (used in lab study) was absent from D10 plots 1 month after treatment (Amossé et al. 2018).

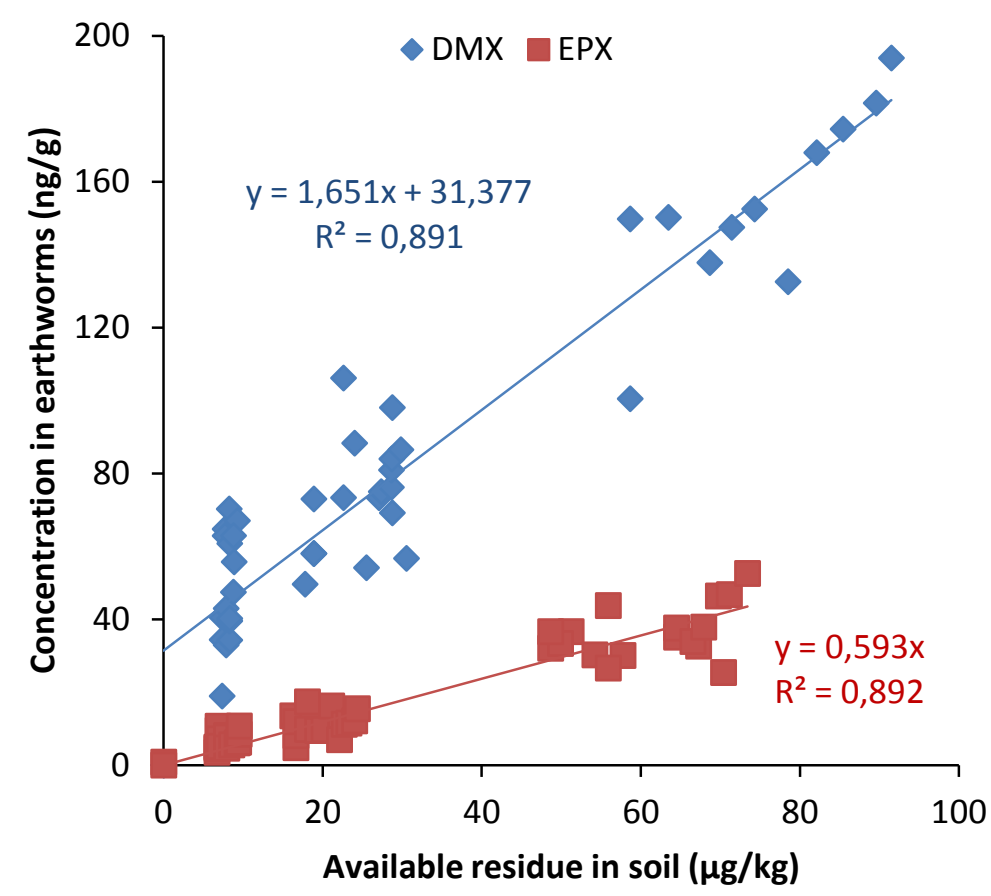

Fig. 4 Fungicide residues in earthworms as a function of available residues in the soil during the laboratory study at all exposure times. DMX: Dimoxystrobin, EPX: Epoxiconazole 
In the laboratory study, a linear correlation was found between available residues in soil and concentrations in earthworms (Figure 4). No significant intercept was found in the equation obtained for EPX, traducing proportionality between EPX environmental availability and concentration in earthworms. The slope of $0.593 \pm$ 0.034 was significantly lower than 1 , showing that the extraction with HPCD was not as efficient as in our previous study mimicking the environmental bioavailability of EPX to earthworms (Nélieu et al. 2016). This could be due to differences in soil characteristics, tested commercial formulations (Opus® in Nélieu et al. 2016 versus Swing® Gold in this study), soil water content (90\% WHC in Nélieu et al. 2016 vs 70\% in this study) and/or because of differences in earthworm species (A. icterica in Nélieu et al. 2016 vs A. caliginosa here). The linear model was adequate for DMX and EPX, with $\mathrm{R}^{2}$ regression coefficients of 0.891 and 0.892 , respectively. The slope of the line in the DMX regression was higher than $1(1.65 \pm 0.17)$ but there was also a large intercept of $31.4 \pm 6.9$. To interpret this atypical equation, the notions of steady-state and bioaccumulation factor (BAF) were considered. As a steady-state classically occurs between 3 and 14 days (Svobodová et al. 2018; Chang et al. 2016; Jager et al. 2005), a steady state can be assumed in this study where the minimum exposure time was 28 days. This legitimised the calculation of a BAF, using the ratio of the concentration in earthworms / total concentration in soil for $\mathrm{BAF}_{\text {tot }}$ or concentration in earthworms / available concentration in soil for $\mathrm{BAF}_{\text {avail }}$ (Figure S5). The BAF were independent of exposure time, reinforcing the steady-state assumption. However, the two active substances clearly showed different BAF patterns. For EPX, the ratio was roughly independent of the dose, with an average of $0.32 \pm 0.09$ and $0.68 \pm 0.24$ for $\mathrm{BAF}_{\text {tot }}$ and $\mathrm{BAF}_{\text {avail, }}$, respectively. This quasiindependence is consistent with that observed for various chemicals (Lanno et al. 2004; Gaw et al. 2012). In contrast, the $\mathrm{BAF}_{\mathrm{avail}}$ of DMX significantly decreased when the dose increased, with $5.47 \pm 1.72$ at D0.33, 3.08 \pm 0.79 at $\mathrm{D} 1$, and $2.06 \pm 0.25$ at $\mathrm{D} 3$. These changes between doses were less striking for $\mathrm{BAF}_{\mathrm{tot}}$, but this factor was still significantly lower at D3. A dose effect on the ratio was previously observed for some insecticides and other chemicals in earthworms (Chang et al. 2016; Jager et al. 2005). Three reasons were proposed to explain this effect. First, there could have been a change in the availability of the fungicide in soil. However this was not applicable in our case as environmental availability was demonstrated to be not dose-dependent. Second, earthworm behaviour may have changed, with earthworms becoming rather inactive to limit bioaccumulation. However, as the BAF of the co-pollutant and thus co-ingested EPX was not dose-dependent, this does not appear to be the reason. Finally, a plausible factor for the observations with DMX in the present study was an increase in the efficiency of the earthworms to excrete or metabolise the chemical when they were exposed to higher doses. This hypothesis is supported by the change in metabolism observed by Chang et al. (2016), which evidenced that increasing the dose of a pesticide led to a higher excretion of its main metabolite.

\section{Conclusions}

Here we showed that total, available and bioavailable concentrations of two widely used fungicides (DMX and EPX) were highly heterogeneous under field conditions, which make difficult data interpretation. However, dissipation rates and environmental availabilities displayed similar trends between field and laboratory experiments, even if the experimental conditions largely differed, considering for instance the presence of vegetation and the earthworm species. Dimoxystrobin was less persistent, less available, but bioaccumulated more in earthworms than epoxiconazole. The two chemicals we tested also differed in their sorption to soil constituents and their sensitivity (regarding bioaccumulation factor in earthworms) to the applied dose, which was not expected from available data. This study of the different steps assessing chemical bioavailability in different situations, regarding their fate and interactions with living organisms, represent a step toward a better understanding of the behaviour of the two considered active substances in the environment. Further research should be devoted to determine the link between environmental and toxicological bioavailability of the two fungicides in laboratory and field experiments.

\section{Acknowledgements}

We thank Christophe Montagnier and Arnaud Huré (experimental unit, INRA), Marc Hanrio and Florent Viala (park department, INRA) for the rental and the mowing of the meadow before pesticide application. We also 
thank Sébastien Breuil, Jean-Pierre Pétraud, Jodie Thénard and Véronique Etiévant (Ecosys, INRA) for their help in pesticide applications in the field, field samplings and maintenance of the earthworm breeding, as well as Laure Mamy (Ecosys, INRA) for the $\mathrm{K}_{\mathrm{f}}$ evaluations.

\section{Funding information}

A part of this study was funded by ANSES (French Agency for Food, Environmental and Occupational Health \& Safety), grant agreement CRD-2015-23_PPV15, which provided a post-doctoral grant to Joël Amossé. We also thank the IDEX Paris-Saclay, which funded the -IDI 2015\| project (ANR-11-IDEX-0003-02) and provided half-funded Ph.D. scholarships for Sylvain Bart. The other half was provided by INRA (Environment and Agronomy Division).

Conflict of interest: The authors declare that they have no conflict of interest.

\section{References}

Ahmad R, James TK, Rahman A, Holland PT (2003) Dissipation of the herbicide Clopyralid in an allophanic soil: Laboratory and Field Studies. J Environ Sci Health B 38(6):683-695. https://doi.org/10.1081/PFC120025553

Amossé J, Bart S, Péry ARR, Pelosi C (2018) Short-term effects of two fungicides on enchytraeid and earthworm communities under field conditions. Ecotoxicology 27(3):300-312. https://doi.org/10.1007/s10646-018-1895-7

Bart S, Laurent C, Péry ARR, Mougin C, Pelosi C (2017) Differences in sensitivity between earthworms and enchytraeids exposed to two commercial fungicides. Ecotox Environ Saf 140:177-184. https://doi.org/10.1016/j.ecoenv.2017.02.052

Bart S, Amossé J, Lowe C, Mougin C, Péry ARR, Pelosi C (2018) Aporrectodea caliginosa, a relevant earthworm species for a posteriori pesticide risk assessment: current knowledge and recommendations for culture and experimental design. Environ Sci Pollut Res 25:33867-33881. https://doi.org/10.1007/s11356018-2579-9

Bending GD, Lincoln SD, Edmondson RN (2006) Spatial variation in the degradation rate of the pesticides isoproturon, azoxystrobin and diflufenican in soil and its relationship with chemical and microbial properties. Environ Pollut 139:279-287. https://doi.org/10.1016/j.envpol.2005.05.011

Beulke S, Dubus IG, Brown CD, Gottesbüren B (2000) Simulation of pesticide persistence in the field on the basis of laboratory data - A Review. J Environ Qual 29(5):1371-1379. https://doi.org/10.2134/jeq2000.00472425002900050001x

Bolan NS, Baskaran S (1996) Characteristics of earthworm casts affecting herbicide sorption and movement. Biol Fertil Soils 22:367-372. https://doi.org/10.1007/BF00334585

Bouché MB (1972) Lombriciens de France. Ecologie et Systématique. INRA Ann Zool Ecol Anim Publication, France

Čadková E, Komárek M, Kaliszová R, Vaněk A, Balíková M (2013) Tebuconazole sorption in contrasting soil types. Soil Sedim Contam 22(4):404-414. https://doi.org/10.1080/15320383.2013.733448 
Chabauty F, Pot V, Bourdat-Deschamps M, Bernet N, Labat C, Benoit P, (2016) Transport of organic contaminants in subsoil horizons and effects of dissolved organic matter related to organic waste recycling practices. Environ Sci Pollut Res 23:6907-6918. https://doi.org/10.1007/s11356-015-5938-9

Chai LK, Wong MH, Bruun Hahnsen HC (2013) Degradation of chlorpyrifos in humid tropical soils. J Environ Manag 125:28-32. https://doi.org/10.1016/j.jenvman.2013.04.005

Chang J, Wang Y, Wang H, Li J, Xu P (2016) Bioaccumulation and enantioselectivity of type I and type II pyrethroid pesticides in earthworm. Chemosphere 144:1351-1357. https://doi.org/10.1016/j.chemosphere.2015.10.011

Chaplain V, Mamy L, Vieublé-Gonod L, Mougin C, Benoit P, Barriuso E, Nélieu S (2011) Fate of pesticides in soils: toward an integrated approach of influential factors. In: Stoytcheva M (ed) Pesticides in the modern world - Risks and benefits. Intech, pp 535-560. https://doi.org/10.5772/17035

Cryer SA (2005) Determining kinetic and nonequilibrium sorption behavior for Chlopyrifos using a hybrid batch/column experiment. J Agric Food Chem 53:4103-4109. https://doi.org/10.1021/jf050238c

De Santo FB, Guerra N, Vianna MS, Machado Torres JP, Marchioro CA, Niemeyer JC (2019) Laboratory and field tests for risk assessment of metsulfuron-methylbased herbicides for soil fauna. Chemosphere 222:645655. https://doi.org/10.1016/j.chemosphere.2019.01.145

Di HJ, Aylmore LAG, Kookana RS (1998) Degradation rates of eight pesticides in surface and subsurface soils under laboratory and field conditions. Soil Sci 163(5):404-411. https://doi.org/10.1097/00010694199805000-00008

FOCUS (2006) Guidance document on estimating persistence and degradation kinetics from environmental fate studies on pesticides in EU registration. Report of the FOCUS Work Group on Degradation Kinetics, EC Document Reference Sanco/10058/2005 version 2.0, 434 pp.

Gaw S, Northcott G, Kim N, Wilkins A, Jensen J (2012) Comparison of earthworm and chemical assays of the bioavalability of aged 1,1-dichloro-2,2-bis(p-chlorophenyl)ethylene, 1,1,1-trichloro-2,2-bis(pchlorophenyl)ethane, and heavy metals in orchard soils. Environ Toxicol Chem 31(6):1306-1316. https://doi.org/10.1002/etc.1817

Ghosh RK, Singh N (2009) Effect of organic manure on sorption and degradation of azoxystrobin in soil. J Agric Food Chem 57:632-636. https://doi.org/10.1021/jf802716f

Harmsen J (2007) Measuring bioavailability: from a scientific approach to standard methods. J Environ Qual 36:1420-1428. https://doi.org/10.2134/jeq2006.0492

Herrero-Hernández E, Marín-Benito JM, Andrades MS, Sánchez-Martín MJ, Rodríguez-Cruz MS (2015) Field versus laboratory experiments to evaluate the fate of azoxystrobin in an amended vineyard soil. J Environ Manag 163:78-86. https://doi.org/10.1016/j.jenvman.2015.08.010

Hoke R, Huggett D, Brasfield S, Brown B, Embry M, Fairbrother A, Kivi M, Paumen ML, Prosser R, Salvito D, Scroggins R (2015) Review of laboratory-based terrestrial bioaccumulation assessment approaches for organic chemicals: current status and future possibilities. Integr Environ Assess Manag 12:109-122. https://doi.org/10.1002/ieam.1692

ISO 11268-3 (2014) Soil quality — Effects of pollutants on earthworms - Part 3: Guidance on the determination of effects in field situations. ISO, Geneva.

ISO 17402 (2008) Soil quality - guidance for the selection and application of methods for the assessment of bioavailability of contaminants in soil and soil materials. ISO, Geneva. 
Jager T, Van Der Wal L, Fleuren RHLJ, Barendregt A, Hermens JLM (2005) Bioaccumulation of organic chemicals in contaminated soils: evaluation of bioassays with earthworms. Environ Sci Technol 39:293-298. https://doi.org/10.1021/es035317o

Jänsch S, Frampton GK, Römbke J, Van Den Brink P, Scott-Fordsmand JJ (2006) Effects of pesticides on soil invertebrates in model ecosystem and field studies: a review and comparison with laboratory toxicity data. Environ Toxicol Chem 25(9):2490-2501. https://doi.org/10.1897/05-439R.1

Karas PA, Baguelin C, Pertile G, Papadopoulou ES, Nikolaki S, Storck V, Ferrari F, Trevisan M, Ferrarini A, Fornasier F, Vasileiadis S, Tsiamis G, Martin-Laurent F, Karpouzas DG(2018) Assessment of the impact of three pesticides on microbial dynamics and functions in a lab-to-field experimental approach. Sci Tot Environ 637-638:636-646. https://doi.org/10.1016/j.scitotenv.2018.05.073

Karlsson AS, Weihermüller L, Tappe W, Mukherjee S, Spielvogel S (2016) Field scale boscalid residues and dissipation half-life estimation in a sandy soil. Chemosphere 145:163-173. https://doi.org/10.1016/j.chemosphere.2015.11.026

Lanno R, Wells J, Conder J, Bradham K, Basta N (2004) The bioavailability of chemicals in soil for earthworms. Ecotoxicol Environ Saf 57:39-47. https://doi.org/10.1016/j.ecoenv.2003.08.014

Lavelle P (1996) Diversity of soil fauna and ecosystem function. Biol Int 33:3-16. http://www.documentation.ird.fr/hor/fdi:010008126

Liu X, Wu H, Hu T, Chen X, Ding X (2018) Adsorption and leaching of novel fungicide pyraoxystrobin on soils by ${ }^{14} \mathrm{C}$ tracing method. Environ Monit Assess 190:86. https://doi.org/10.1007/s10661-017-6458-5

Lowe CN, Butt KR (2005) Culture techniques for soil dwelling earthworms: a review. Pedobiologia 49, 401-413. https://doi.org/10.1016/j.pedobi.2005.04.005

Mc Donald JA, Gaston LA, Jackson SS, Locke MA, Zablotowicz RM (2006) Degradation kinetics assessment for the fungicide BAS 505 in intact soil cores versus batch soils. Soil Sci 171(3):239-248. https://doi.org/10.1097/01.ss.0000187375.38649.5b

Mc Donald J, Gaston L, Elbana T, Andres K, Cranfield E (2013) Dimoxystrobin sorption and degradation in sandy loam soil: impact of different landscape positions. Soil Sci 178(12):662-670. https://doi.org/10.1097/SS.0000000000000030

Nélieu S, Delarue G, Ollivier E, Awad P, Fraillon F, Pelosi C (2016) Evaluation of epoxiconazole bioavailability in soil to the earthworm Aporrectodea icterica. Environ Sci Pollut Res 23:2977-2986. https://doi.org/10.1007/s11356-015-5270-4

Neuwirthová N, Bílková Z, Vašíčková J, Hofman J, Bielská L (2018) Concentration/time-dependent dissipation, partitioning and plant accumulation of hazardous current-used pesticides and 2-hydroxyatrazine in sand and soil. Chemosphere 203:219-227. https://doi.org/10.1016/j.chemosphere.2018.03.177

OECD (2000) OECD guidelines for the testing of chemicals. Adsorption - Desorption using a batch equilibrium method.

Paoletti MG (1999) The role of earthworms for assessment of sustainability and as bioindicators. Agric Ecosyst Environ 74 (1-3):137-155. https://doi.org/10.1016/S0167-8809(99)00034-1

Papadopoulou ES, Karas PA, Nikolaki S, Storck V, Ferrari F, Trevisan M, Tsiamis GT, Martin-Laurent F, Karpouzas DG (2016) Dissipation and adsorption of isoproturon, tebuconazole, chlorpyrifos and their main transformation products under laboratory and field conditions. Sci Tot Environ 569-570:86-96. https://doi.org/10.1016/j.scitotenv.2016.06.133 
Pose-Juan E, Rial-Otero R, Paradelo M, Simal-Gándara J, Arias M, López-Periago JE (2010) Behaviour of metalaxyl as copper oxychloride-metalaxyl commercial formulation vs. technical grade-metalaxyl in vineyards-devoted soils. J Hazard Mater 174:181-187. https://doi.org/10.1016/j.jhazmat.2009.09.034

PPDB (2020) https://sitem.herts.ac.uk/aeru/ppdb/en/atoz/htm

Reddy SN, Gupta S, Gajbhiye VT (2013) Adsorption-desorption and leaching of pyraclostrobin in Indian soils. J Environ Sci Health B 48:948-959. https://doi.org/10.1080/03601234.2013.816600

Reid BJ, Stokes JD, Jones KC, Semple KT (2000) Nonexhaustive cyclodextrin-based extraction technique for the evaluation of PAH bioavailability. Environ Sci Technol 34:3174-3179. https://doi.org/10.1021/es990946c

Semple KT, Doick KJ, Jones KC, Burauel P, Craven A, Harms H (2004) Defining bioavailability and bioaccessibility of contaminated soil and sediment is complicated. Environ Sci Technol 38:228A-231A. https://doi.org/10.1021/es040548w

Shan J, Xu J, Zhou W, Ji L, Cui Y, Gio H, Ji R (2011) Enhancement of chlorophenol sorption on soil by geophagous earthworms (Metaphire guillelmi). Chemosphere 82:156-162. https://doi.org/10.1016/j.chemosphere.2010.10.047

Svobodová M, Smídová K, Hvezdová M, Hofman J (2018) Uptake kinetics of pesticides chlorpyrifos and tebuconazole in the earthworm Eisenia andrei in two different soils. Environ Pollut 236:257-264. https://doi.org/10.1016/j.envpol.2018.01.082

Wu X, Long Y, Li J, Li R, Liu R, Li M (2015) Degradation of metolachlor in tobacco field soil. Soil Sedim Contam 24:398-410. https://doi.org/10.1080/15320383.2015.968765

Wu P, Wu WZ, Han ZH, Yang H (2016) Desorption and mobilization of three strobilurin fungicides in three types of soil. Environ Monit Assess 188:363. https://doi.org/10.1007/s10661-016-5372-6

Zhang W, Jiang F, Ou J (2011) Global pesticide consumption and pollution: with China as a focus. Proceedings of the International Academy of Ecology and Environmental Sciences 1:125-144.

Zhao S, Arthur EL, Coats JR (2003) Influence of Microbial Inoculation (Pseudomonas Sp. Strain ADP), the Enzyme Atrazine Chlorohydrolase, and Vegetation on the Degradation of Atrazine and Metolachlor in Soil. J Agric Food Chem 51:3043-3048. https://doi.org/10.1021/jf025954i 


\title{
Supplementary material
}

\author{
Environ. Sci. Pollut. Res.
}

Soil dissipation and bioavailability to earthworms of two fungicides under laboratory and field conditions

\begin{abstract}
S. Nélieu ${ }^{a}{ }^{*}$, G. Delarue ${ }^{a}$, J. Amossé ${ }^{b}$, S. Bart ${ }^{b}$, A.R.R. Péry ${ }^{b}$, C. Pelosi ${ }^{b}$
a UMR ECOSYS, INRA, AgroParisTech, Université Paris-Saclay, 78850, Thiverval-Grignon, France

${ }^{\mathrm{b}}$ UMR ECOSYS, INRA, AgroParisTech, Université Paris-Saclay, 78026, Versailles, France

* Corresponding author (S. Nélieu): UMR ECOSYS INRA AgroParisTech, Bâtiment EGER, Avenue Lucien Brétignières, 78850 Thiverval Grignon, France. Tel: (+33)1.30815283. E-mail: sylvie.nelieu@inra.fr
\end{abstract}

D1 D10

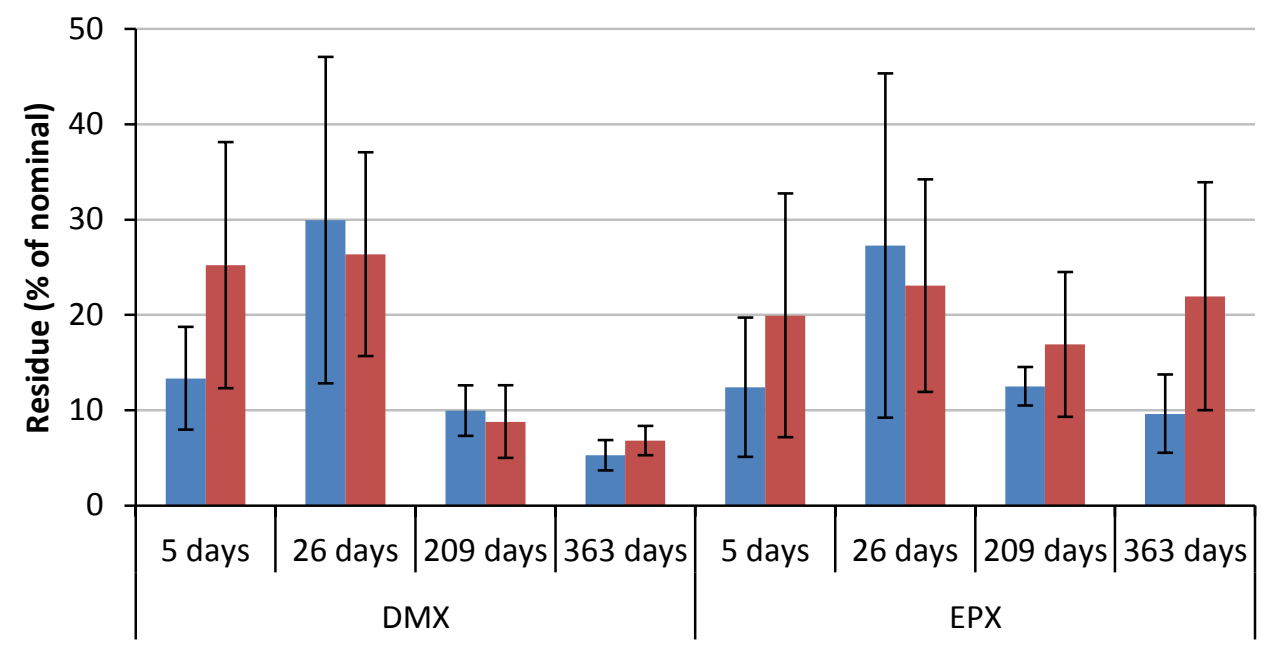

Figure S1. Dimoxystrobin (DMX) and epoxiconazole (EPX) residues in 0-10 cm soils, in the field, in \% of nominal dose (mean and standard deviation of plots, $n=4$ ). 

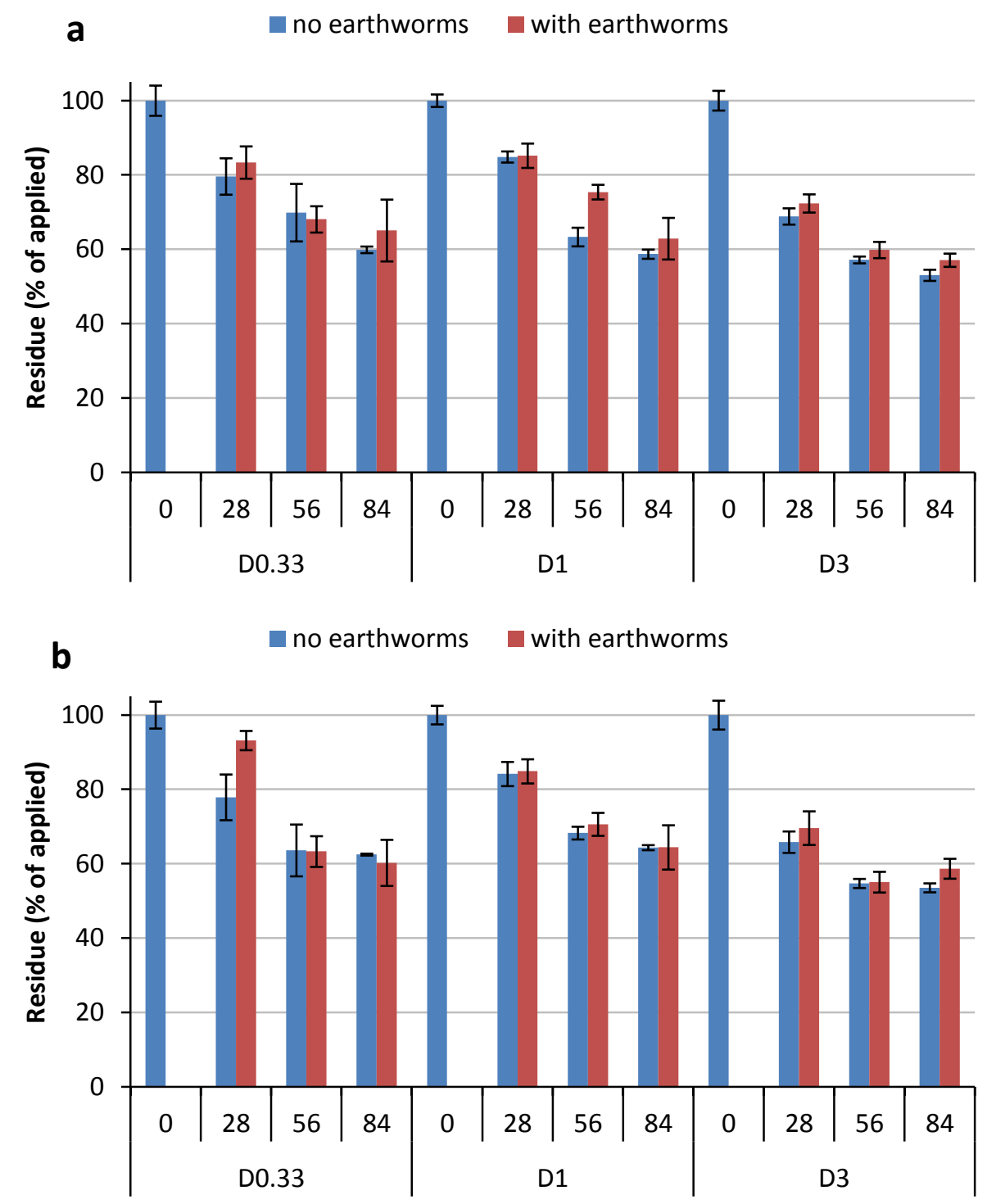

Figure S2. Dimoxystrobin (a) and epoxiconazole (b) residues in soils, during laboratory studies in the presence or not of earthworms (mean and standard deviation of replicates, $n=4)$.<smiles>CNC(=O)/C(=N/OC)c1ccccc1COc1cc(C)ccc1C</smiles><smiles>Fc1ccc(C2(Cn3cncn3)OC2c2ccccc2Cl)cc1</smiles>

Figure S3. Chemical structures of dimoxystrobin (left) and epoxiconazole (right) 

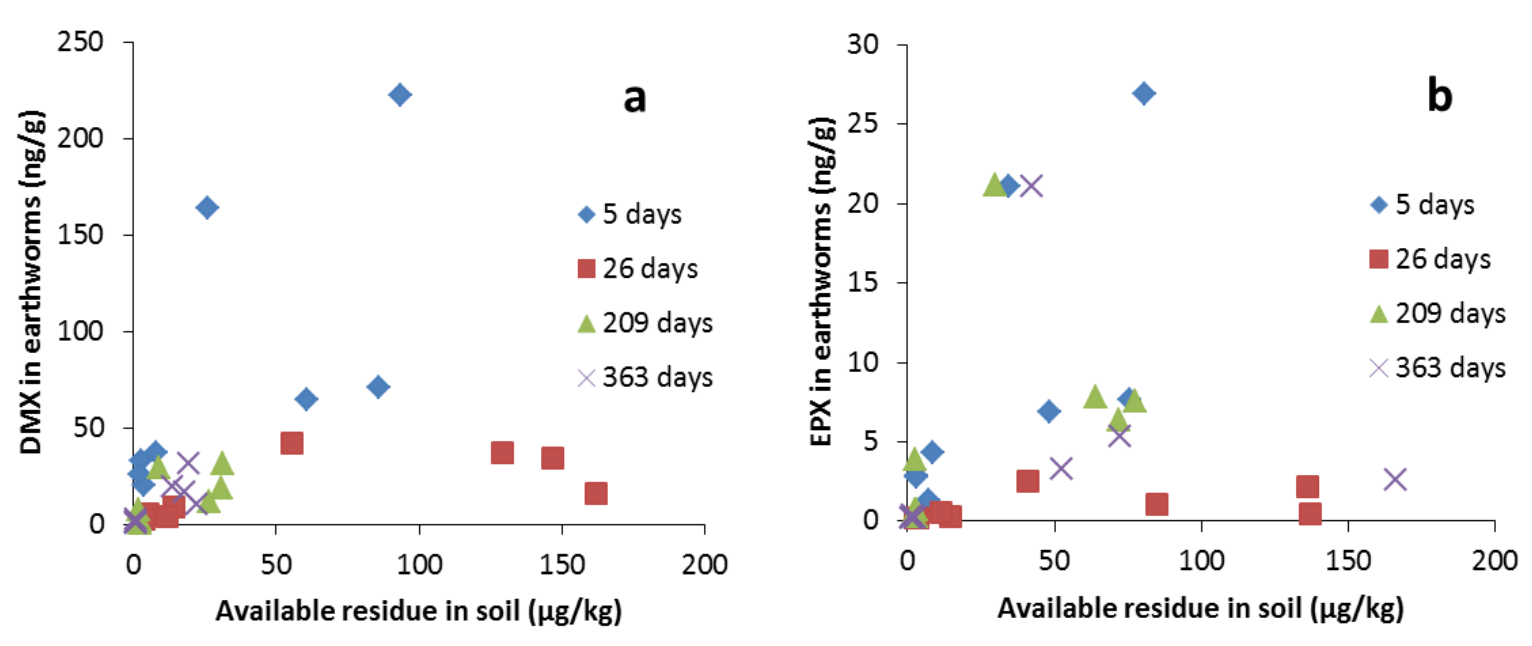

Figure S4. Pesticides residues in earthworms as a function of available residue in soil during field experiments: dimoxystrobin (a) and epoxiconazole (b).
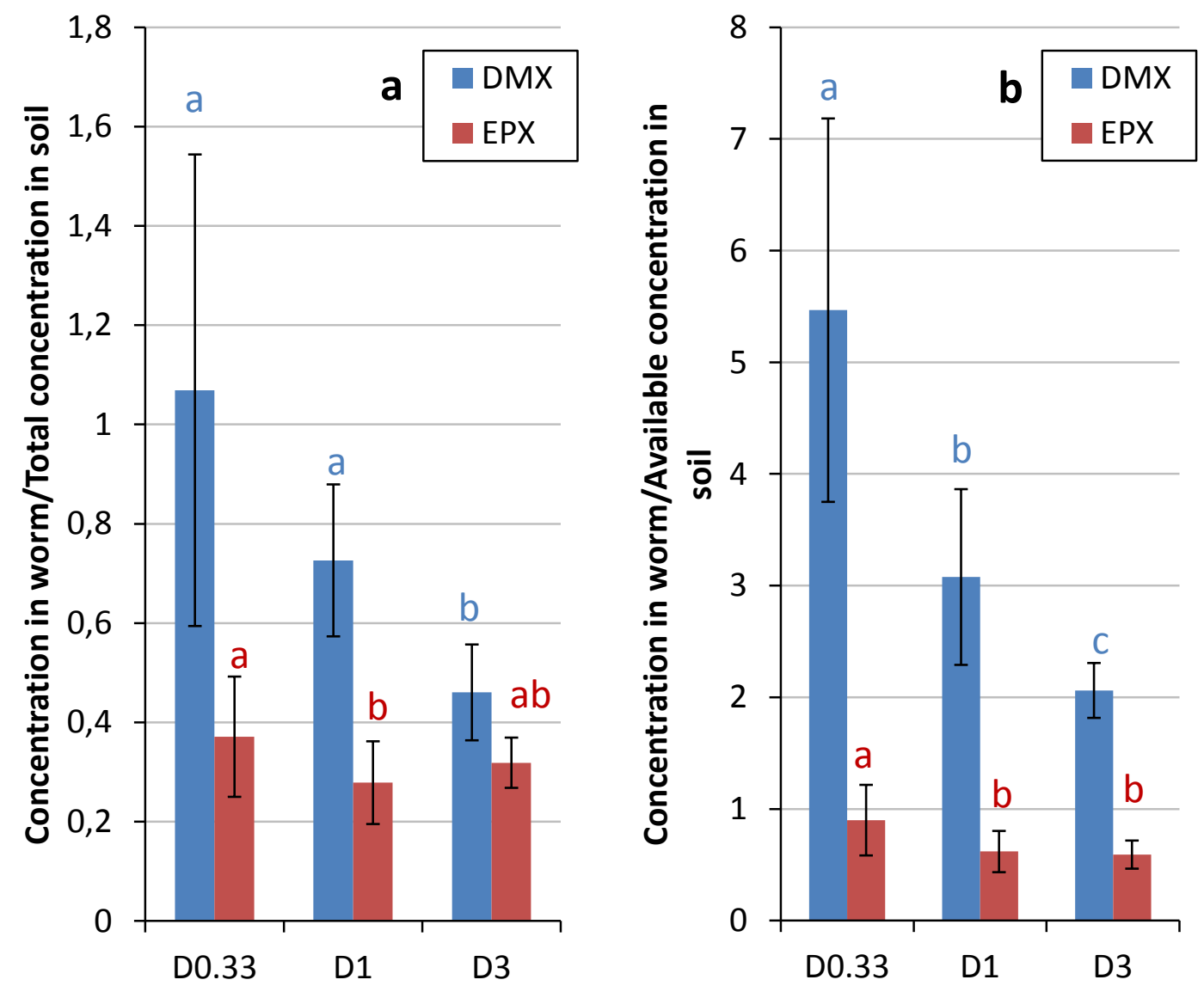

Figure S5. Ratio of concentration observed in earthworms (fresh weight) and soil (dry weight) during laboratory experiments: total concentration (a) and environmentally available concentration (b). DMX: Dimoxystrobin, EPX: Epoxiconazole. 